\title{
Property development during the COVID-19 pandemic: challenges and outlook in Malaysia
}

\author{
Zainab T. Jagun $^{1,2} \cdot$ Bemgba B. Nyakuma $^{3}$ (1) $\cdot$ Dzurllkanian Daud $^{1} \cdot$ Salfarina Samsudin ${ }^{1}$
}

Received: 2 August 2021 / Accepted: 23 December 2021 / Published online: 5 January 2022

(c) The Author(s), under exclusive licence to Springer-Verlag GmbH Germany, part of Springer Nature 2022

\begin{abstract}
Through administrative research and media records, this paper aims to examine and highlight the effects of the COVID-19 pandemic on Malaysian workers, property development, construction sites, and the national economy. The development of real estate and the construction industry can significantly impact socio-economic growth and infrastructure development. Adequate building and infrastructure construction can ensure national economic stability, job creation, community cohesion, and higher living standards. Since the COVID-19 pandemic began in 2019, many countries, including Malaysia, have reported an increased number of virus cases. According to the Ministry of Health, 9316 cases and 314 COVID-19 clusters were discovered in Malaysia, with a 38.55-48.06\% prevalence for factories, a $12.55-15.29 \%$ prevalence for community spreading, an $8.6-11.56 \%$ prevalence for construction sites, a 5.53-7.96\% prevalence for educational sites, and a $7.01 \%$ prevalence for shopping areas. Several governments-imposed lockdowns, movement, and proximity restrictions during the pandemic due to the high infection rates at property development sites. However, due to inactivity in various sectors such as the construction industry, these measures have significantly impacted the national economy. As a result, the pandemic has had an impact on workers, production costs, and project completion timelines, resulting in operational issues and policy concerns. Overall, the records reviewed revealed that the COVID-19 pandemic has significantly impacted real estate development, the housing market, and the construction industry. As a result, sustained and targeted policies are required to support Malaysia's construction industry's socio-economic growth and infrastructure development.
\end{abstract}

Keywords COVID-19 · Pandemics · Property development · Construction industry

\section{Introduction}

Property development contributes significantly to the national economy by bringing economic stability, creating jobs, fostering community cohesion, and preserving or increasing home values (Ab Hamid 2015; Jagun 2020; Özogul and Tasan-Kok 2020). Property developments in

Responsible Editor: Philippe Garrigues

Bemgba B. Nyakuma

bbnyax1@gmail.com

1 Department of Real Estate, Faculty of Built Environment and Survey, Universiti Teknologi Malaysia, Skudai, Johor, Malaysia

2 Department of Estate Management, the Federal Polytechnic, Offa, Kwara State, Nigeria

3 Department of Chemistry, Faculty of Sciences, Benue State University, Makurdi, Benue State, Nigeria profits and politics in Asia are increasingly regulated (Chen and Shin 2019a; Schmidt 2019). To make property development a profitable venture, governments began intervening in housing policies and market-driven practices. With these two roles, governments can expand their control over public and private property development (Bragaglia and Caruso 2020). Malaysian government policies and regulations have increased the development of new project units in Malaysia. Several workers and on-site development projects and construction activities have been involved over time. It has led to massive ongoing developments across the country. The mass of workers on site has influenced the spread of COVID-19 because construction involves physical contact and a high likelihood of transmission due to contact between several workers is substantial (Gan and Koh 2021). Increased viral infections have resulted in federal lockdowns, proximity restrictions, and movement controls (MCO). Conversely, the virus and pandemic control measures have negatively impacted national businesses and economies (Siegrist et al. 
2021). Similarly, the COVID-19 pandemic has harmed Malaysia's construction industry and economy (Gamil and Alhagar 2020). Except for critical or critical services, most construction projects have been halted in Malaysia. Even after the MCO was lifted, contractors faced strict standard operating procedures (SOPs) and various occupational health and safety guidelines on construction sites. As shown in the study on the effects of a pandemic on the construction industry's survival, the changes have hampered construction work (Gamil and Alhagar 2020). The findings have raised awareness of the most severe consequences of sudden pandemic emergence. Between 22 February and 2 April 2021, the Ministry of Health reported 314 COVID-19 clusters, $38.55 \%$ for factories, $15.29 \%$ for community spreading, $8.60 \%$ for construction sites, $7.96 \%$ for educational sites, and $7.01 \%$ for shopping areas. The term "pandemic" refers to more than just a health-related concept (Barah 2021). It also brings about changes that may impact all sectors and professions, including the movement and speed of construction sites. With such conditions, developers are expected to build for more extended periods, resulting in waste of building materials and negative consequences for local public health and safety. As a result of the current economic climate, other construction-related practical difficulties that have a negative impact on the rate of return on investment become prevalent (Zamani et al. 2021). The COVID-19 outbreak is a stark reminder that pandemics, like other rare disasters, have happened and will continue to happen. Even if we cannot stop dangerous viruses from spreading, we can plan for their consequences (Donthu and Gustafsson 2020).

The COVID-19 pandemic has hampered Malaysian property development. First, the coronavirus crisis revealed new operational and policy issues relating to construction worker management. Second, the COVID-19 pandemic has raised questions about the current business model for building sites. Third, how does high COVID-19 transmission and infection rate impact site, given that worker infection is no longer acceptable? According to Megahed and Ghoneim (2020), even in the post-Coronavirus era, international best practices for property development remain uncertain. Thus, controlling the COVID-19 pandemic could take years. Malaysia has imposed several entries and movement restrictions due to the COVID-19 pandemic. These constraints have increased uncertainty and new challenges for project operations (Shah et al. 2020).

During the pandemic, property development sites must be protected to prevent COVID-19 transmission (Ong et al. 2021). The COVID-19 pandemic has slowed construction progress in existing developments, according to a REHDA survey. Likewise, REHDA's findings from the " $2 \mathrm{H} 2020$ Property Industry Survey" (1H2021 and 2H2021) show that 121 members responded to the study from 12 October through 30 October 2020. In total, $78 \%$ anticipate that their land banking reinvestment plans and future projects will be severely affected. According to the survey, $81 \%$ of the respondents experienced cash flow issues, with the majority $(82 \%)$ having difficulty paying their human resource and management expenses. The majority (94\%) experienced a decrease in business activities, and $88 \%$ had seen profits fall from $44 \%$ to $40 \%$ in 2019.

Consequently, about $35 \%$ of the respondents plan to impose wage cuts to reduce running the businesses. In comparison, $65 \%$ have opted for alternative means of saving money, including freezing new recruitment, increasing staff, zero bonuses, and reducing other expenses such as marketing. Not enough work has been done to estimate how long it will last and how much it will cost to keep the companies running. The impact of outbreaks or clusters on workers, production costs, and project completion has become a source of concern. The property development industry will undoubtedly change dramatically in the next decade as consumers begin to think more about their lifestyle, finances, and time. Moreover, the importance customers place on their immediate environment and related issues will grow over time. Thus, the impact of COVID-19 and pandemic-related problems in the construction industry must be emphasized. Using administrative, research, and media records, the study will assess the impact of the COVID-19 outbreak on construction workers, property development, and administration. The economic assessment and property development data were chosen to highlight the current global pandemic and Malaysian construction industry nexus. However, the discussion inspires us to examine the challenges facing the property development industry in COVID-19. The study's research questions are as follows:

1 Examine the impact of COVID-19 on workers, property development, construction sites, and the Malaysian economy.

2 Suggest future collaboration with stakeholders and governments to address pandemic-related issues.

\section{Methodology}

This paper employs the systematic review methodology. This methodology is motivated by its advantages of being systematic, transparent, and replicable. Previous review articles also influence it (Sharma et al. 2021a, 2021b; Zutshi et al. 2021). Various databases such as Scopus, Google Scholar, and Web of Science were used to search for records. The use of such databases ensure that the articles meet a consistent standard. We discovered 44 records using keywords such as "COVID-19," "construction," "property development," and "economy." Because the COVID-19 issue is for 2020, the records are fewer in number, nonetheless, given that property 
development and the construction industry have a significant impact on socio-economic growth and infrastructure development. Because proper building and infrastructure construction ensure national economic stability, job creation, community cohesiveness, and improved living standards, we believe it is worthwhile to review this critical field. These records were then filtered based on titles and abstracts. It was discovered that 39 of the papers fit our theme, while the remaining five did not. These 39 papers were chosen for further examination. Table 1 displays the selected papers. We decided on a cluster analysis of the selected papers' keywords to arrive at the appropriate themes studied in these papers. We identified four clusters: employee, production cost, project completion, and operational issue. These clusters serve as the themes for our work, and the keywords of the 39 records are grouped within these themes, as shown in Table 2.

\section{Existing literature review}

After a review of the listed papers, it was discovered that 5 of 44 publications do not meet the inclusion criteria (as detailed in the methodology section). Therefore, we conducted a systematic review of 39 studies to synthesize their findings and outline future research in this field. The housing market and construction industry have been severely hampered because of the epidemic. We discovered that inactivity in many industries, such as construction, has significantly impacted the national economy. Our work is organized around four major themes: employee, production cost, project completion, and operational problem. This paper proposes a coping mechanism centered on the operational issue. The outline covers project management, human factors, attitude, policy response, and government reform. The paper is laid out as follows: In the final section, a policy outline to address the challenges posed by COVID-19 for property development, the housing market, and the construction industry is presented. Following this investigation, four clusters were identified, as shown in Table 2.

However, it is worth noting that, according to the review conducted, there are authors who analyze the pandemic from a variety of perspectives, all of which agree that there has been an impact from COVID-19 on construction site workers involving health and safety (Abu Aisheh et al. 2021; Tanrıvermiş 2020). In the property development industry, production costs have an impact on distribution, contribution, economic stability, and the construction phase (Gan and Koh 2021; King et al. 2021; Simpeh and Amoah 2021). Project completion in terms of potential impact, reviving emerging markets, consequences, financing, and challenges for the construction industry are all important considerations (Alaloul et al. 2021a, 2021b; Jaya et al. 2021; Shah et al.
2020). The project manager, practitioners, human factors, attitude, policy response, and government reform are all involved in the operational problem (Alenezi 2020; Sharma et al. 2020; Simpeh and Amoah 2021; Tanrıvermiş 2020). However, with the construction site operation, the economy is usually affected by a pandemic like COVID-19, let alone a societal lockdown effect. As a result, the construction and real estate development industries, among others, will suffer greatly because they rely on a diverse workforce.

\section{Relevance of property development to the economy}

Various studies show that property development and construction have a significant impact on global economic growth (Tanrıvermiş 2020). This viewpoint is based on the idea that adequate building and infrastructure construction ensures that nations achieve social development, industrialization, freight transportation, sustainable development, and urbanization (Alaloul et al. 2021b). Therefore, Malaysia's economy is shifting toward more sustainable production, emphasizing the construction industry. For starters, the construction industry is not only the backbone of any country's economic growth, but it is also one of the largest emitters of greenhouse gases, particularly carbon dioxide $\left(\mathrm{CO}_{2}\right)$ (Kajaste and Hurme 2016; Wong et al. 2020). Thus, developing economies rely heavily on the construction industry to implement long-term socio-economic and infrastructure development plans (Abu Aisheh et al. 2021; Ogunbode et al. 2021). Unforeseen disasters, such as the COVID-19 epidemic, can significantly impact the overall GDP and the contributing industries (Abbas et al. 2021; Sharma et al. 2020).

According to the Department of Statistics and Central Bank (Bank Negara Malaysia), the Malaysian economy grew by 3.6\% in the fourth quarter Q4 of the fiscal year of 2019 . However, after that, the nation's GDP began to decline as the consequences of the COVID-19 pandemic hit harder. This scenario was exacerbated by the lockdowns (MCO and $\mathrm{CMCO}$ ) in Malaysia following the first reported cases of COVID-19. The MCO was implemented in five (5) states Selangor, Penang, Johor, Malacca, and Sabah, and the federal territories of Kuala Lumpur, Putrajaya, and Labuan. In addition, the MCO was later implemented in Kelantan and Sibu (Sarawak).

Furthermore, MCO 2.0 was extended until 4 March 2021 for Selangor, Penang, Johor, and Kuala Lumpur, and until the date for all other states and federal territories, excluding Sarawak, due to many cases. As a result, many sectors of the economy, such as the construction industry, were forced to close. However, domestic economic recovery occurred in the second half of 2020 , with analysts predicting a positive 


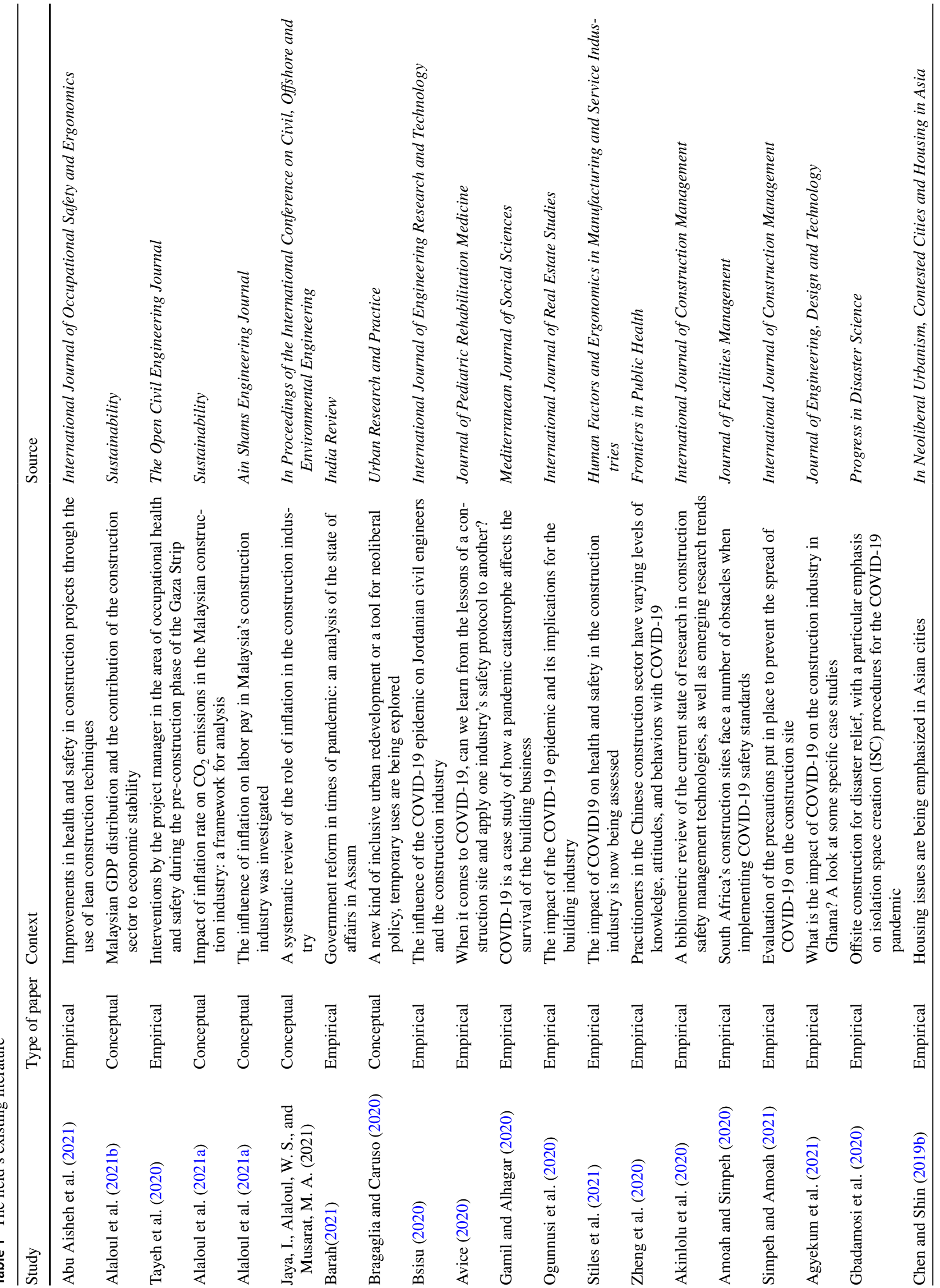




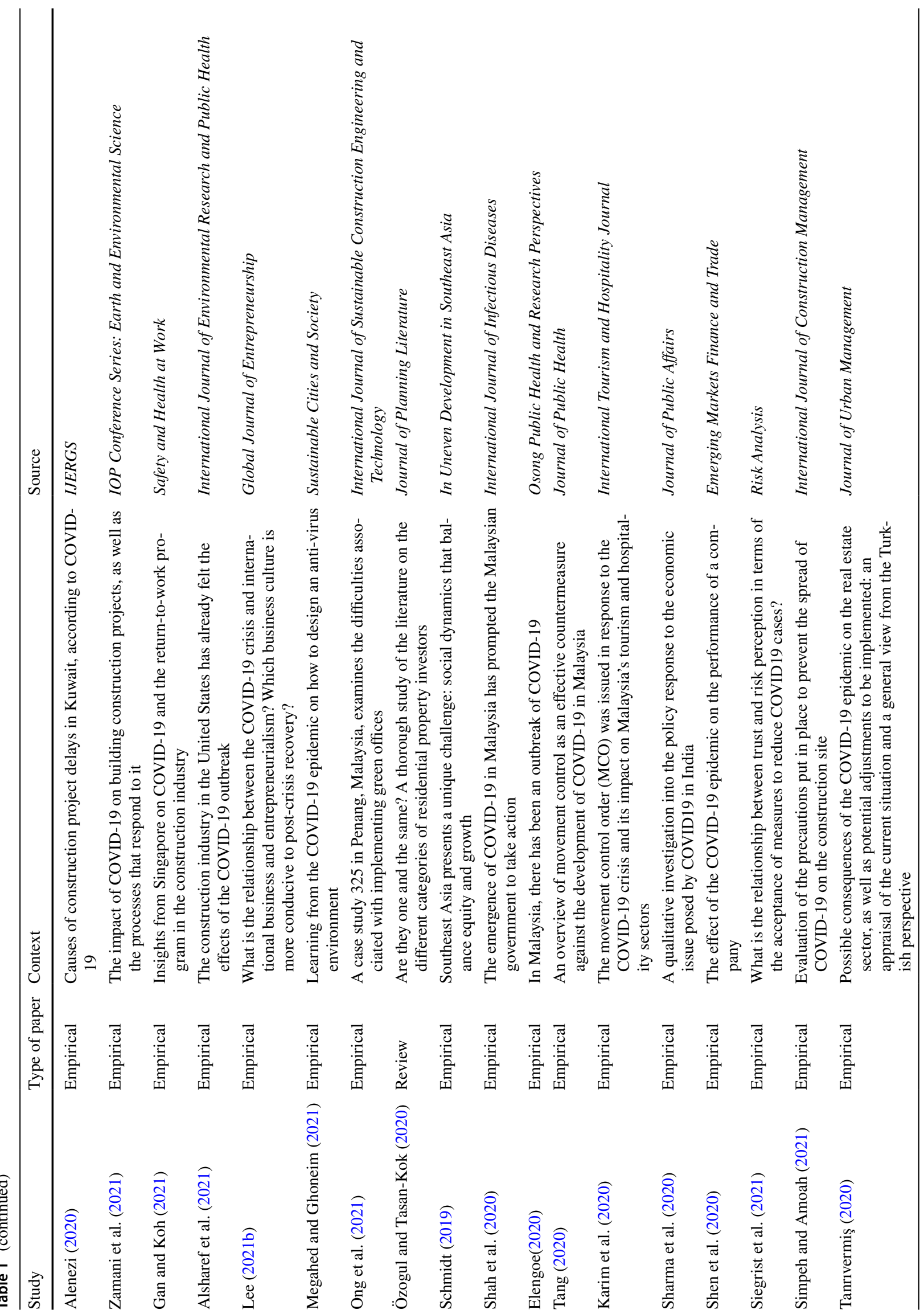


Table 2 Keywords and clusters

\begin{tabular}{ll}
\hline Keyword & Cluster \\
\hline Health & Employee \\
Occupational health & \\
Safety & \\
Construction site/phase & \\
COVID-19 & \\
Pandemic/epidemic & Production cost \\
MCO & \\
Distribution & \\
Contribution & \\
Economic stability & \\
Construction phase & \\
GDP & \\
Labor & \\
Investment problem & \\
Balance equity & \\
Inflation & \\
Potential impact & \\
Reviving emerging market & \\
Consequences & \\
Finance & \\
Challenges & \\
Project manager & \\
practitioners & \\
Human factors & \\
attitude & \\
Policy response & \\
Government reform & \\
&
\end{tabular}

outlook for 2021. Nevertheless, the rally is expected to be uneven and influenced by various factors, such as the duration of the COVID-19 pandemic and vaccine deployment. Other important considerations include the magnitude of external spillovers, sector-specific trends, and the degree of improvement in labor market conditions.

According to the year 2020 records, the construction sector accounts for $4.0 \%$ of the GDP of Malaysia. The construction industry's growth has accelerated, with annual changes of $-19.4 \%$ from 2020 to $13.4 \%$ in 2021 . Furthermore, growth in the civil engineering subsector is expected to accelerate as construction activity on significant infrastructure projects increases over time. Moreover, end-of-life projects are expected to boost growth in the trade subsector. However, there is growing concern that the increasing number of COVID-19 infections linked to construction sites will result in additional lockdowns, affecting property development and the Malaysian economy. In addition, there are reports of several financial vulnerabilities evident before and after the pandemic. According to the January 2021 Global Financial Stability Review (GFSR), the pandemic has triggered rising corporate and 
sovereign debt, non-bank financial institution sector fragilities, and declining banking sector profitability in some economies (International Monetary Fund, 2021). Due to the increasing number of cases and the future implementation of lockdowns. Therefore, it is necessary to examine the situation and offer solutions critically. Furthermore, sustained and targeted policy actions will be required to support economic and industry growth in an unpredictable operating environment.

\section{Impact of COVID-19 on property development}

The consequences of the COVID-19 pandemic on performance were examined by Shen et al. (2020). Based on data from publicly traded Chinese enterprises, the findings showed that COVID-19 has a negative impact on company performance. According to the study, COVID-19 has a greater negative impact on the performance of firms with small-scale investments, particularly in high-impact areas and industries. Similar studies show that the COVID-19 epidemic has resulted in lower demand, softer business moods, and increased uncertainty, leaving little opportunity for growth (Lee 2021a). However, the statistics of the potential output growth for Malaysia shows an expected slow of 3.3\% in 2020 as at $4.8 \%$ in 2019. Furthermore, investment activity contracted in 2020 by $-14.5 \%$ compared to $-2.1 \%$ in 2019 . This is due to lower investment activity, which makes firms unlikely to invest in productive capital. Consequently, there is lower total factor productivity (TFP) growth (e.g., machinery, equipment, and ICT). Furthermore, the worsening prospects of the job market and increased unemployment during the year lowered the participation of the labor force in 4Q of 2020 by $68.5 \%$ and $68.7 \%$ in 2019. Lastly, the MCO period and accompanying SOPs have had a negative influence on labor productivity, which is projected to have a negative impact on TFP.

\section{Policy outline for property development amid COVID-19}

The number of daily cases reported in each cluster is a vital pandemic metric. From 22 February to 2 April 2021, 9316 people were affected in 314 clusters. The data shows that most instances of COVID-19 originated in factories (48.06\%), followed by community spreads $(12.55 \%)$, constructions $(11.56 \%)$, detention centers (5.62\%), and educational sites (5.53\%). Numerous researchers have looked into COVID-19's impact on industrial output and the national economy. Due to the current state of uncertainty, the pandemic's impact on the property development industry is limited. Among these researches is the study of Ogunnusi et al. (2020) that addresses the consequences and prospects of the COVID-19 epidemic in the construction industry. The study investigated the impact of COVID-19 on construction procurement and potential opportunities. Contrasting COVID-19 with force majeure in standard construction contract forms revealed some challenges in the areas of disruption of workflow and supply chain, new policy issues, and worker anxiety. The study concluded that virtual working and distinctive design are urgently needed in modern procurement planning to address existing concerns and create new opportunities. Likewise, Bsisu (2020) investigated the COVID-19 pandemic on Jordanian civil engineers and the construction industry. The study investigated engineers' challenges during lockdowns, expected outcomes, and outlook on the Jordanian civil engineering and construction industry. The findings show that design-based civil engineers could work efficiently from home during lockdowns. Simpeh and Amoah (2021) investigated construction site precautions to prevent COVID-19 from spreading among workers. The findings show that most construction companies have taken the necessary precautions to prevent COVID-19 from spreading on-site.

Moreover, some construction firms developed new protocols to prevent COVID-19 from spreading on-site. However, some construction firms did not follow the suggested measures.

Overall, the studies found that COVID-19 exacerbated existing issues in property development, the housing market, and the construction industry. Before the virus outbreak, developers were concerned about the near-term market outlook, and the downturn could last for years. Because Malaysia uses the sales-then-build (STB) housing supply system, which allows developers to secure profits before projects begin, it is reasonable to assume that developers are more aware of future market prospects. Furthermore, COVID-19 caused operational and financial problems, and financial assistance and complete information are required to overcome these consequences, confirming COVID-19's severe impact on the construction industry. There are, however, few studies that have solely focused on the impact of the pandemic on property development in the construction industry as of July 2021. Furthermore, the pandemic has significantly impacted national GDP because most Malaysian construction sites have closed. As a result, the pandemic's impact on property development, the construction industry, and national GDP must be highlighted further.

\section{COVID-19 pandemic on the employee, production cost, project completion, and operational problem for property development industry}

According to the review cluster, the pandemic has had a significant impact on cash flow problems, which the majority of contractors have experienced due to the COVID-19 pandemic (Ogunnusi et al. 2020; Sharma et al. 2020). This 
observation is made because the work completed is typically assessed in project payments (Agyekum et al. 2021). It has been impossible to find a job and receive payment due to the suspension of nearly all construction activities during the MCO. Despite this, the contractors continued to incur operational costs such as rental, wages, and overheads (Shen et al. 2020). The fundamental contractual obligation for contractors is to conduct and complete the contract's construction works within the specified time frames. When a contractor fails to complete work within the specified time frame, an employer or client can impose liquidated damages and sometimes other charges or, in the worst case, terminate the contract (Alenezi 2020). However, when the projects were suspended, or all site activities ceased in Malaysia, many contractors successfully claimed extensions of time for lockdowns during the MCO period under the contract giving them an extension in project completion.

However, many property developers in Malaysia faced challenges after the initial MCO period. After the MCO, new health and safety SOPs, worker shortages, and time restrictions became common challenges. The worker limits imposed by social distancing requirements were also a source of disruption. These uncertainties and disturbances have undoubtedly reduced productivity and pushed back project completion dates, increasing contractor costs. Sadly, productivity loss is challenging to detect and assess, so the consequences for a building project are frequently ignored. Measuring productivity loss can include measured mile, earned value, and program analyses. However, relevant studies require sufficient and precise contemporaneous documents and data. Such records are also required to show the link between disruptions and productivity losses.

\section{Research priorities for the foreseeable future}

As a result of COVID-19, there have been unprecedented human deaths in life-altering situations. The COVID-19 pandemic is affecting research in all fields because of the severity of the pandemic shock and impact. We can expect to see economic, environmental, and social setbacks, and policy recommendations to address them in COVID-19 research. The property development industry must respond quickly and effectively to this pandemic situation to ensure the long-term viability of this sector of our economy, which contributes significantly to the national economy by bringing economic stability, creating jobs, and fostering community cohesion.

\section{Conclusion}

The paper investigated and highlighted the effects of the COVID-19 pandemic on property development, the construction industry, and Malaysia's national economy. The COVID19 pandemic's impact on property developers and development in Malaysia's construction industry was also examined. Construction accounts for $4 \%$ of Malaysia's GDP, according to data and media records reviewed. Because of this, the discovery of 9316 infections from 314 clusters raised severe health and safety concerns. The findings also revealed that property development sites had one of the highest infection rates, prompting the government to implement lockdowns, proximity restrictions, and MCOs to prevent the virus from spreading. However, the measures significantly impacted the national economy and GDP, owing to the construction industry's inactivity. Furthermore, the pandemic affected workers' wellbeing, production costs, and project completion timelines, resulting in operational issues and policy concerns. The records also revealed that, even after the MCOs were lifted, contractors faced work disruptions and strict occupational health and safety SOP guidelines on building/construction sites. Worker shortages, restricted working hours, supply chain delays, lengthy suspensions, and disruption due to worker limits imposed by social distancing requirements are other challenges. Overall, these factors have hampered the efficient operation of construction work, reduced productivity, and caused additional delays in project completion deadlines, resulting in increased expenses for contractors. Overall, the records reviewed revealed that the COVID-19 pandemic has significantly impacted real estate development, the housing market, and the construction industry. As a result, sustained and targeted policy actions are required to support growth and development in Malaysia's construction industry and economy.

Author contribution Zainab T. Jagun, Bemgba B. Nyakuma: writingoriginal draft and data curation. Dzurllkanian Daud, Salfarina Samsudin: writing — review and editing. Salfarina Samsudin: supervision.

Availability of data and material The data used in this manuscript is included in the text.

Code availability Not applicable.

\section{Declarations}

Ethics approval Not applicable.

Consent to participate Not applicable.

Consent for publication Not applicable.

Competing interests The authors declare no competing interests. 


\section{References}

Ab Hamid MRB (2015) Value-based performance excellence model for higher education institutions. Quality \& Quantity 49:1919-1944

Abbas J, Mubeen R, Iorember PT, Raza S, Mamirkulova G (2021) Exploring the impact of COVID-19 on tourism: transformational potential and implications for a sustainable recovery of the travel and leisure industry. Current Research in Behavioral Sciences 2:100033

Abu Aisheh YI, Tayeh BA, Alaloul WS, Almalki A (2021) Health and safety improvement in construction projects: lean construction approach International journal of occupational safety and ergonomics: $1-26$

Agyekum K, Kukah AS, Amudjie J (2021) The impact of COVID-19 on the construction industry in Ghana: the case of some selected firms Journal of Engineering, Design and Technology

Akinlolu M, Haupt TC, Edwards DJ, Simpeh F (2020) A bibliometric review of the status and emerging research trends in construction safety management technologies International Journal of Construction Management:1-13

Alaloul WS, Musarat MA, Liew M, Qureshi AH, Maqsoom A (2021a) Investigating the impact of inflation on labour wages in construction industry of Malaysia. Ain Shams Engineering Journal 12:1575-1582

Alaloul WS, Musarat MA, Rabbani MBA, Iqbal Q, Maqsoom A, Farooq W (2021b) Construction Sector Contribution to Economic Stability: Malaysian GDP Distribution Sustainability 13:5012

Alenezi TAN (2020) COVID-19 causes of delays on construction projects in Kuwait. IJERGS 8:6-9

Alsharef A, Banerjee S, Uddin S, Albert A, Jaselskis E (2021) Early impacts of the COVID-19 pandemic on the United States construction industry. International Journal of Environmental Research and Public Health 18:1559

Amoah C, Simpeh F (2020) Implementation challenges of COVID-19 safety measures at construction sites in South Africa Journal of Facilities Management

Avice T (2020) COVID-19: Lessons from a construction site, can we apply one industry safety protocol to another? Journal of Pediatric Rehabilitation Medicine 13:433-437

Barah P (2021) Recasting governance in the times of pandemic: a case study of Assam. India Review 20:213-228

Bragaglia F, Caruso N (2020) Temporary uses: a new form of inclusive urban regeneration or a tool for neoliberal policy? Urban Research \& Practice: $1-21$

Bsisu KA-D (2020) The impact of COVID-19 pandemic on Jordanian civil engineers and construction industry. International Journal of Engineering Research and Technology 13:828-830

Chen Y-L, Shin HB (2019a) Centering housing questions in Asian cities. In: Neoliberal Urbanism, Contested Cities and Housing in Asia. Springer, pp 1-19

Chen Y-L, Shin HB (2019b) Neoliberal urbanism, contested cities and housing in Asia. Springer

Donthu N, Gustafsson A (2020) Effects of COVID-19 on business and research. Elsevier

Elengoe A (2020) COVID-19 outbreak in Malaysia. Osong Public Health and Research Perspectives 11:93

Gamil Y, Alhagar A (2020) The impact of pandemic crisis on the survival of construction industry: a case of COVID-19. Mediterranean Journal of Social Sciences 11:122-122

Gan WH, Koh D (2021) COVID-19 and return-to-work for the construction sector: lessons from Singapore safety and health at work

Gbadamosi A-Q, Oyedele L, Olawale O, Abioye S (2020) Offsite construction for emergencies: a focus on isolation space creation
(ISC) measures for the COVID-19 pandemic. Progress in Disaster Science 8:100130

Jagun ZT (2020) Risks in feasibility and viability appraisal process for property development and the investment market in Nigeria Journal of Property Investment \& Finance

Jaya I, Alaloul WS, Musarat MA Role of inflation in construction: a systematic review. In: Proceedings of the International Conference on Civil, Offshore and Environmental Engineering, 2021. Springer, pp 701-708

Kajaste R, Hurme M (2016) Cement industry greenhouse gas emissions-management options and abatement cost. Journal of Cleaner Production 112:4041-4052

Karim W, Haque, A., Anis, Z., \& Ulfy, M. A. (2020).

King S, Rahman R, Fauzi M, Haron A Mechanisms for addressing the impact of COVID-19 on infrastructure projects. In: IOP Conference Series: Earth and Environmental Science, 2021. vol 1. IOP Publishing, p 012047

Lee Y-F (2021a) COVID-19 crisis and international business and entrepreneurship: which business culture enhances post-crisis recovery? Global Journal of Entrepreneurship 1:1-15

Lee Y-F (2021b) COVID-19 crisis and international business and entrepreneurship: which business culture enhances post-crisis recovery? Global Journal of Entrepreneurship:1

Megahed NA, Ghoneim EM (2020) Antivirus-built environment: Lessons learned from COVID-19 pandemic. Sustainable cities and society $61: 102350$

Megahed NA, Ghoneim EM (2021) Indoor air quality: rethinking rules of building design strategies in post-pandemic architecture. Environmental Research 193:110471

Ogunbode EB, Nyakuma BB, Jimoh RA, Lawal TA, Nmadu HG (2021) Mechanical and microstructure properties of cassava peel ashbased kenaf bio-fibrous concrete composites Biomass Conversion and Biorefinery: https://doi.org/10.1007/s13399-13021-0158813396 https://doi.org/10.1007/s13399-021-01588-6

Ogunnusi M, Hamma-Adama M, Salman H, Kouider T (2020) COVID19 pandemic: the effects and prospects in the construction industry International journal of real estate studies 14

Ong YS, Yusof NA, Osmadi A (2021) Challenges of green office implementation: a case study in Penang, Malaysia International Journal of Sustainable Construction. Eng Technol 12:153-163

Özogul S, Tasan-Kok T (2020) One and the same? A Systematic Literature Review of Residential Property Investor Types Journal of Planning Literature 35:475-494

Schmidt JD (2019) The challenge from South East Asia: social forces between equity and growth. In: Uneven Development in South East Asia. Routledge, pp 21-44

Shah AUM et al (2020) COVID-19 outbreak in Malaysia: actions taken by the Malaysian government. International Journal of Infectious Diseases 97:108-116

Sharma GD, Talan G, Jain M (2020) Policy response to the economic challenge from COVID-19 in India: a qualitative enquiry. Journal of Public Affairs 20:e2206

Sharma GD, Thomas A, Paul J (2021) Reviving tourism industry postCOVID-19: a resilience-based framework. Tourism management perspectives 37:100786

Sharma GD, Tiwari AK, Jain M, Yadav A, Srivastava M (2021b) COVID-19 and environmental concerns: a rapid review renewable and sustainable energy reviews: 111239

Sharma GD, Tiwari AK, Talan G, Jain M (2021) Revisiting the sustainable versus conventional investment dilemma in COVID-19 times. Energy Policy 156:112467

Shen H, Fu M, Pan H, Yu Z, Chen Y (2020) The impact of the COVID19 pandemic on firm performance. Emerging Markets Finance and Trade 56:2213-2230 
Siegrist M, Luchsinger L, Bearth A (2021) The impact of trust and risk perception on the acceptance of measures to reduce COVID-19 cases. Risk Analysis 41:787-800

Simpeh F, Amoah C (2021) Assessment of measures instituted to curb the spread of COVID-19 on construction site International Journal of Construction Management:1-19

Stiles S, Golightly D, Ryan B (2021) Impact of COVID-19 on health and safety in the construction sector Human Factors and Ergonomics in Manufacturing \& Service Industries

Tang KHD (2020) Movement control as an effective measure against COVID-19 spread in Malaysia: an overview Journal of Public Health: $1-4$

Tanrıvermiş H (2020) Possible impacts of COVID-19 outbreak on real estate sector and possible changes to adopt: a situation analysis and general assessment on Turkish perspective. Journal of Urban Management 9:263-269

Tayeh BA, Yaghi RO, Abu Aisheh YI (2020) Project manager interventions in occupational health and safety during the pre-construction phase in the Gaza Strip The Open Civil Engineering Journal 14

Wong SL, Nyakuma BB, Nordin AH, Lee CT, Ngadi N, Wong KY, Oladokun O (2020) Uncovering the dynamics in global carbon dioxide utilization research: a bibliometric analysis (1995-2019) Environmental Science and Pollution Research https://doi.org/10. 1007/s11356-020-11643-w

Zamani S, Rahman R, Fauzi M, Yusof L Effect of COVID-19 on building construction projects: impact and response mechanisms. In: IOP Conference Series: Earth and Environmental Science, 2021. vol 1. IOP Publishing, p 012049

Zheng L, Chen K, Ma L (2020) Knowledge, attitudes, and practices towards COVID-19 among construction industry practitioners in China. Frontiers in public health 8:981

Zutshi A, Mendy J, Sharma GD, Thomas A, Sarker T (2021) From challenges to creativity: enhancing SMEs' resilience in the context of COVID-19 sustainability 13:6542

Publisher's note Springer Nature remains neutral with regard to jurisdictional claims in published maps and institutional affiliations. 